\title{
Helping Infant Economies Grow: Foundations of Trade Policies for Developing Countries
}

\author{
By Bruce Greenwald and Joseph E. StiglitZ*
}

Conventional wisdom has it that trade enhances economic efficiency and thus promotes growth. At least since Robert M. Solow's (1957) pioneering work, however, technological progress has been recognized as the dominant factor in determining the rate of growth. This is presumably even more true for developing countries, for which the possibilities of closing the knowledge gap with advanced industrial countries offers especially large growth potential. We examine the impact of trade restrictions in economies in which technological spillovers within countries and across industries are fundamental to the process of growth (see Kenneth J. Arrow, 1962a, 1962b; Paul M. Romer, 1986; Stiglitz, 1987). Since that work, it has been clear that markets, by themselves, do not necessarily, or in general, lead to overall dynamic efficiency; and that there are often trade-offs between static inefficiencies (e.g., associated with patent protection) and long-term growth. We find, here in particular, that the dynamic benefits of broad trade restrictions may outweigh their static costs. Our analysis provides the basis of an infant economy (as opposed to an infant industry) argument for protection.

This paper develops a simple two-sector model with an industrial (modern) and a traditional (craft or agricultural) sector. There are four key features to the model: (a) there are spillovers from the industrial sector to the craft sector, for which firms in the industrial sector are not compensated; (b) such spillovers are geographically based, that is, it is only productivity increases in the industrial sector in the developing countries that affect productivity increases in the traditional sector; (c) innovations are concentrated in the industrial sector; and (d)

\footnotetext{
* Greenwald: Columbia Business School, Columbia University, Uris Hall, Room 405B, 3022 Broadway, New York, NY 10027 (e-mail: bg7@ columbia.edu); Stiglitz: Columbia Business School, Columbia University, Uris Hall, Room 814, 3022 Broadway, New York, NY 10027 (e-mail: jes322@columbia.edu).
}

size is among the important determinants of the pace of innovation in the industrial sector.

Earlier critiques of trade policies encouraging the development of the industrial sector in developing countries ignored these spillovers. They argued, in effect, that Korea would always have a comparative advantage in growing rice; therefore, it was foolish for it to try to restrict imports of industrial goods, even if by so doing productivity in the industrial goods sector was increased. It could never catch up, so the protection would have to be permanent. Year after year, the country would have been better off if it simply specialized in its own comparative advantage, growing rice. Korea could, and did, catch up, however, at least in certain areas. If catch-up is possible, then dynamic comparative advantage differs from static comparative advantage. But even if Korea's comparative advantage remained in agriculture, industrial protection might be desirable, because by supporting it, one might have a more dynamic agricultural (traditional) sector. Trade restrictions enhance the size of the industrial sector; the benefits spill over to the rural sector; and national income grows at a possibly far faster pace. After presenting the model, we explain why the underlying hypotheses are plausible and argue that the model is broadly consistent with historical experience and empirical evidence.

\section{The Basic Model}

We will consider a highly simplified world consisting of two economies-one developed $(D)$ and the other less developed $(L)$. (The limitation to two economies is inessential; our model could equally consist of multiple (identical) versions of each of the two types of economies.) These economies produce two types of goods-one industrial $(I)$ and the other agricultural/craft $(A)$. (Again, we could easily extend the model to include a multiplicity of goods in each category.) Both are produced 
using only labor as an input, with technologies that at any point in time embody constant-returns-to-scale. We define:

- $C_{I}^{D}\left(C_{A}^{D}\right) \equiv$ amount of labor per unit of industrial (agricultural) output in the developed economy;

- $C_{I}^{L}\left(C_{A}^{L}\right) \equiv$ amount of labor per unit of industrial (agricultural) output in the lessdeveloped economy.

We assume that the developed economy enjoys absolute advantages in the production of both goods (i.e., $C_{I}^{D}<C_{I}^{L}$ and $C_{A}^{D}<C_{A}^{L}$ ), but that the less-developed economy enjoys a comparative advantage in agricultural/craft production. Thus,

$$
\frac{C_{A}^{D}}{C_{I}^{D}}>\frac{C_{A}^{L}}{C_{I}^{L}} .
$$

We further assume that the developed economy is very large relative to the less-developed economy, in particular, that it is capable of supporting the entire global demand for industrial output and at the same time producing significant amounts of agricultural/craft output. Thus, in equilibrium, the less-developed economy is fully specialized in agricultural/craft production, while the developed economy produces both goods.

Prices will be determined by the trade-off in the developed economy between the cost of producing the industrial good and the cost of producing the agricultural/craft good. If we designate the agricultural/craft good as numeraire with price unity, then the price of the industrial good in the developed economy will be

$$
P_{I}^{D}=C_{I}^{D} / C_{A}^{D}
$$

and wages in the industrial economy will be

$$
W^{D}=1 / C_{A}^{D} .
$$

In the less-developed economy, again using the agricultural/craft output as numeraire with price unity, the wage level will be

$$
W^{L}=1 / C_{A}^{L},
$$

which is, of course, lower than the wage level in the developed economy since $C_{A}^{L}>C_{A}^{D}$.

\section{A. Free Trade Equilibrium}

Since $C_{I}^{D} / C_{A}^{D}<C_{I}^{L} / C_{A}^{L}$, industrial production in the less-developed economy is not economically viable. It specializes in agriculture. The composition of consumption in the less-developed economy is then determined by the real price, $p_{I}^{D}$. The composition of output in the industrial economy is determined by the global demand (its own demand plus the imports of the less-developed economy) for industrial goods. Finally, note that in this simple static equilibrium all the gains from trade accrue to the less-developed economy.

\section{B. Dynamic Development}

We now introduce technological progress into this static equilibrium. Formally, we will assume, first, that productivity improvement affects the industrial and agricultural/craft sectors equally, i.e.,

$$
-\frac{1}{C_{I}} \cdot \frac{d C_{I}}{d t}=-\frac{1}{C_{A}} \cdot \frac{d C_{A}}{d t}
$$

so that

$$
-\frac{d}{d t}\left[\frac{C_{I}}{C_{A}}\right]=-\frac{C_{I}}{C_{A}}\left[\frac{1}{C_{I}} \cdot \frac{d C_{I}}{d t}-\frac{1}{C_{A}} \cdot \frac{d C_{A}}{d t}\right]=0 .
$$

Whatever drives productivity, increases spillover-fully, from one sector within the economy to the other. This has one important simplifying implication: productivity growth does not affect the price of industrial goods relative to agricultural/craft goods. (Our results require only that there be some spillovers from the industrial to the traditional sector within a country.) Productivity growth results from (a) research and development efforts which, while originally devoted to one sector, have benefits that inevitably spill over to other sectors; (b) human capital improvements, which, again while they arise in one sector, inevitably migrate with labor to other sectors of the economy; and (c) the accumulated knowledge and attention of managers and engineers, which, although developed in one sector, also naturally migrates to other sectors. 
Next, we assume that the rate of technological progress, $g$, is determined by

$$
\begin{aligned}
g & =-\frac{1}{C_{I}} \cdot \frac{d C_{I}}{d t}=-\frac{1}{C_{A}} \cdot \frac{d C_{A}}{d t} \\
& =f\left(\frac{Q_{1}}{Q_{1}+Q_{A}}\right), \quad f(0)=0, \quad f^{1}>0
\end{aligned}
$$

where $Q_{I}$ is the output of the industrial sector and $Q_{A}$ is the output of the agricultural/crafts sector. This assumes that the forces driving productivity growth originate in the industrial sector of the economy and have an aggregate impact that is proportional to the (relative) size of the industrial sector.

The process of productivity growth described by equations (1) and (2) has important long-run consequences for our two economies. The lessdeveloped economy, with $Q_{I}^{L}=0$, stagnates. Without an industrial sector there is no productivity growth. In contrast, the developed economy experiences productivity growth at a rate

$$
g^{D}=f\left(\frac{Q_{I}^{D}}{Q_{I}^{D}+Q_{A}^{D}}\right)
$$

where the composition of output is determined increasingly by its own demands for output, since the less-developed economy becomes a progressively smaller part of the overall global economy. Asymptotically, $g^{D}$ will converge to a rate of growth determined by developed economy conditions alone. Over time, the less-developed economy falls farther and farther behind its developed counterpart.

\section{The Role of Trade Policy}

Consider now the consequences of a ban on industrial imports by the less-developed country (or equivalently the imposition of prohibitively high tariffs). The result would be an immediate welfare loss as it substituted high-cost, domestic industrial production for lower-cost imports from the developed economy. In the new autarkic equilibrium, however, industrial output in the less-developed economy would no longer be zero, and productivity growth would now occur. Just as in the case of the developed economy, a high-tariff, less-developed economy would produce a mix of outputs dependent on its own demands for industrial and agricultural/craft products at a fixed relative price

$$
P_{I}^{L}=\frac{C_{I}^{L}}{C_{A}^{L}} .
$$

If we designate the resulting industrial output by $Q_{I}^{L}$, then the rate of productivity growth will increase from zero to

$$
g^{L}=f\left(\frac{Q_{I}^{L}}{Q_{I}^{L}+Q_{A}^{L}}\right) .
$$

Eventually the benefits of this dynamic improvement in productivity will outweigh the short-term inefficiencies associated with highcost, local industrial production. The country will be better off. Whether the present discounted value of welfare is higher depends on how high $g^{L *}$ is, and how low the discount rate is. Thus, in this context, trade barriers may enhance rather than impair economic welfare.

\section{The Industrial Sector as the Source of Innovation and Spillovers}

\section{A. Knowledge Production}

The key assumption here is that the industrial sector is the source of innovation. The justifications for such an assumption are rooted in the nature of industrial activity. Such activity takes place in firms that (relative to firms in the other sector) are large, long-lived, stable, and densely concentrated geographically. Agricultural/craft production, by contrast, typically takes place on a highly decentralized basis among many small, short-lived, unstable firms. We have also assumed that there are important spillovers, not only within the sector, but to the agricultural/craft sector. These spillovers involve knowledge, human capital, and institutional development. There are several channels through which the specific characteristics of the industrial sector get translated into higher productivity growth for the economy as a whole.

Resources and Incentives for Research and Development.-Since particular innovations 
are far more valuable to large organizations, which can apply them to many units of output, than to smaller ones with lower levels of output (see Dixit and Stiglitz, 1977; Arrow, 1962b), there is far greater incentive to engage in $R \& D$ in the industrial sector than in the agricultural/craft sector. The result will be higher innovation investments in the former sector than in the latter.

Stability and Continuity.-The accumulation of knowledge on which productivity growth is based is necessarily cumulative. This, in turn, greatly depends on a stable organization for preserving and disseminating the knowledge involved, and on continuity in jobs and personnel to support these processes. In large organizations, with the resources to provide redundant capacity where needed, the required degree of stability and continuity is much more likely to be present than in small, dispersed organizations where the loss of single individuals may completely compromise the process of knowledge accumulation. As a result, steady productivity improvement will be more likely to arise from industrial than agricultural/craft production.

The Ability to Support Public R\&D.- - Largescale, densely concentrated activities are far easier to tax than small-scale, dispersed activities. Thus, economies with large, accessible industrial sectors will be far better able to support publicly sponsored R\&D than those consisting largely of dispersed, small-scale agricultural/ craft production units. This factor may be especially important in the support of agricultural research, like that undertaken by Agricultural Extension Service in the United States. These activities directly contribute to agricultural productivity growth, but could not be supported without a taxable base of industrial activity.

Human Capital Accumulation.-Opportunities and incentives for accumulating general human capital are likely to be far greater in large, complex industrial enterprises with a wide range of interdependent activities than in a small, dispersed, narrowly focused agricultural/ craft enterprises. The resulting human capital accumulation is a critical element in both developing the innovations on which productivity growth depends and in disseminating them as workers move between enterprises and across sectors.

Public Support for Human Capital Accumulation.-Just as in R\&D, private capital market failures may mean that public support, in the form of free primary and secondary education, is a critical component of general human capital accumulation. Again, the greater susceptibility of concentrated, industrial enterprises to taxation is key to funding. As they migrate between sectors, ultimately higher productivity growth in the agricultural/craft sector will be engendered as well.

Concentration and Diffusion of Knowledge. -Diffusion of knowledge among densely collocated, large-scale industrial enterprises is likely to be far more rapid than diffusion of knowledge among dispersed, small-scale agricultural/craft enterprises. The resulting economies of scale associated with these spillovers are, therefore, likely to be greater in industrial than in agricultural/craft economies.

Monitoring and Physical Capital Investment and the Development of a Robust Financial Sector-_Although physical capital is not an explicit part of our model, it can be readily extended to include physical capital investment. Greater investment should lead to higher levels of productivity both directly, through capital deepening and the embodiment of technical progress (Solow, 1957), and indirectly, as the capital goods industry is a source of innovation. Investment, in turn, requires that suppliers of capital be able to monitor the performance of firms, and/or that institutions for doing this exist. Industrial firms, because of their large scale, should be less costly to monitor. Hence, an industrial environment should be characterized by a more highly-developed financial sector than an agricultural/craft environment. Once developed, a strong financial sector facilitates capital deployment throughout the economy, even in the rural sector.

Learning to Learn and Cross-Border Knowledge Flows.-Success in the industrial sector requires knowledge and the ability to acquire knowledge that is common across borders. 
Some of this knowledge and these abilities are relevant to the agricultural sector and disseminate to it through mechanisms already described.

\section{B. Knowledge Transmission}

What matters is how knowledge (productivity increases) are generated and transmitted. We have described some of the mechanisms (e.g., labor mobility) through which dissemination across sectors occurs. Our analysis assumed that spillovers are concentrated within national boundaries. This assumption rests on four factors: geographical proximity; international restrictions of movement of labor (and associated movements in knowledge and human capital); language barriers; and historical patterns of social interactions, which are strongly affected by national boundaries. The results of our analysis, however, require only that transmission of knowledge in the agricultural/craft sector be stronger within a country. Indeed, our results are strengthened if there is some element of transmission across countries within the industrial sector, so long as that transmission increases with the size of the industrial sector in the developing country. For the developing country, there is a further reason for promoting the industrial sector: it is the window to the world, the channel through which more advanced knowledge gets transmitted to the developing country for both industry and agriculture. A manufacturer of textiles, for instance, absorbs information about textile production from other countries (perhaps because he buys machines from other countries). But some of that knowledge may be relevant for the agricultural sector.

\section{Theory and Evidence}

There has been a widespread presumption that free trade is good for growth. Yet, the most successful countries, both today (in East Asia) and historically (including the United States), not only engaged in trade restrictions, but those restrictions were an explicit part of their growth strategies. Even war times, in which trade is interrupted, have often seemed to be periods of enormous dynamic gains.

Much of that presumption is based on the observed correlation between growth and trade. But correlation does not prove causality, which may well run from growth to trade. This interpretation is consistent with the absence of a strong relationship between liberalization and growth (see Andrew H. Charlton and Stiglitz, 2005). Trading opportunities available through globalization are universal; yet growth has been highly particular, both across countries (even among those that have liberalized) and within individual countries, over time. It is particular local conditions that determine whether universal trade opportunities lead to growth. Our interpretation is also consistent with numerous historical experiences, including those noted below.

What about countries like India and China, which have liberalized and grown? A closer look at the timing shows that their takeoff occurred prior to trade liberalization, though in both cases it was associated with internal liberalization (see Dani Rodrik and Arvind Subramanian, 2005). Reducing domestic distortions, while maintaining external barriers, provides precisely the conditions for the dynamic gains identified in this paper.

\section{History and Policy}

Our analysis can be used to derive an optimal tariff, balancing the long-term benefits of fostering industrial growth against the short-term costs of inefficient acquisition of industrial products. The model has more general implications about the nature of such tariffs, however. First, tariffs should be broadly and uniformly applied to industrial products. Since the benefits sought are broadly rather than narrowly determined, there should be no attempt to pick winners by supporting particular industries. This has the added benefit of avoiding the creation of narrowly focused special interests concerned with sustaining particular tariffs beyond their natural economic lifetime. Properly designed, both the costs and the benefits of a uniform industrial tariff system should be widely dispersed. Second, a broadly based industrial tariff system should be, to some extent, naturally selflimiting. Successful local industries should begin to export and, therefore, be naturally predisposed to favor free trade. Finally, it may well be that individual national markets are too small to support robust local industries. In that case, the natural extension of the basic policy is 
to combine local economies at similar stages of industrial development into free-trade areas, which are then protected by common uniform, external industrial tariff business.

Ultimately, the test of the effectiveness of such uniform, infant-economy tariff policies is how well they have worked in practice; and here, at least superficially, the historical record is encouraging. The trade policy of the newly formed European Economic Community (EEC) was, in the 1950s, one of high, but relatively uniform, external tariff barriers. The growth of the EEC behind these barriers was rapid. Similarly, Asian economics like Japan, Korea, China, Taiwan, and Singapore have favored broad rather than narrowly tailored barriers to trade, and they have all experienced strong growth. In its early history, the United States also tended to favor high and broadly applied industrial tariffs and succeeded in fostering high levels of growth.

\section{REFERENCES}

Arrow, Kenneth J. "The Economic Implications of Learning by Doing." Review of Economic Studies, 1962(a), 29(3), pp. 155-73.

Arrow, Kenneth J. "Economic Welfare and the Allocation of Resources for Invention," in National Bureau of Economic Research, ed.,
The rate and direction of innovative activity: Economic and social factors. Princeton: Princeton University Press, 1962(b), pp. 609-25.

Dixit, Avinash K. and Stiglitz, Joseph E. "Monopolistic Competition and Optimum Product Diversity." American Economic Review, 1977, 67(3), pp. 297-308.

Rodrik, Dani and Subramanian, Arvind. "From 'Hindu Growth' to Productivity Surge: The Mystery of the Indian Growth Transition." International Monetary Fund, IMF Staff Papers 2005, 52(2), pp. 193-228.

Romer, Paul M. "Increasing Returns and LongRun Growth." Journal of Political Economy, 1986, 94(5), pp. 1002-37.

Solow, Robert M. "Technical Change and the Aggregate Production Function." Review of Economics and Statistics, 1957, 39(3), pp. 312-20.

Stiglitz, Joseph E. "On the Microeconomics of Technical Progress," in Jorge M. Katz, ed., Technology generation in Latin American manufacturing industries. London: Macmillan, 1987, pp. 56-77.

Stiglitz, Joseph E. and Charlton, Andrew H. Fair trade for all: How trade can promote development. Oxford: Oxford University Press, 2005. 
Copyright of American Economic Review is the property of American Economic Association and its content may not be copied or emailed to multiple sites or posted to a listserv without the copyright holder's express written permission. However, users may print, download, or email articles for individual use. 